\title{
Eosinophilic meningitis caused by Angiostrongylus cantonensis: an emergent disease in Brazil
}

\author{
Alessandra Loureiro Morassutti ${ }^{1,2}$, Silvana Carvalho Thiengo ${ }^{3}$, \\ Monica Fernandez ${ }^{3}$, Kittisak Sawanyawisuth ${ }^{4,5}$, Carlos Graeff-Teixeira ${ }^{1,2} /+$ \\ 'Laboratório de Biologia Parasitária, Faculdade de Biociências ²Laboratório de Parasitologia Molecular, \\ Instituto de Pesquisas Biomédicas, Pontifícia Universidade do Rio Grande do Sul, Porto Alegre, RS, Brasil \\ ${ }^{3}$ Laboratório de Malacologia, Instituto Oswaldo Cruz-Fiocruz, Rio de Janeiro, RJ, Brasil ${ }^{4}$ Department of Medicine \\ ${ }^{5}$ Center for Emerging Infectious Diseases, Faculty of Medicine, Khon Kaen University, Khon Kaen, Thailand
}

Eosinophilic meningitis (EoM) is an acute disease that affects the central nervous system. It is primarily caused by infection with the nematode Angiostrongylus cantonensis. This infection was previously restricted to certain Asian countries and the Pacific Islands, but it was first reported in Brazil in 2007. Since then, intermediate and definitive hosts infected with A. cantonensis have been identified within the urban areas of many states in Brazil, including those in the northern, northeastern, southeastern and southern regions. The goals of this review are to draw the attention of the medical community and health centres to the emergence of EoM in Brazil, to compile information about several aspects of the human infection and mode of transmission and to provide a short protocol of procedures for the diagnosis of this disease.

Key words: eosinophilic meningitis - Angiostrongylus cantonensis - emergent in Brazil - algorithm

Nomura and Lin first described eosinophilic meningitis (EoM) caused by Angiostrongylus cantonensis in 1944, based on the observation of a nematode in the cerebrospinal fluid (CSF) of a patient with meningitis (Prociv et al. 2000). EoM caused by $A$. cantonensis may also be referred to as cerebral angiostrongyliasis (CA) or neuroangiostrongyliasis.

A. cantonensis typically occurs in southeast Asian countries and the Pacific Islands. However, this scenario began to change with the first reported occurrence in the Americas in 1981 when infected rats and snails were found in Cuba (Aguiar et al. 1981). Since that time, the occurrence of $A$. cantonensis has been reported in the United States of America, Jamaica and Ecuador (Kim et al. 2002, Slom et al. 2002, Wang et al. 2008, Pincay et al. 2009); it has recently been found in Brazil (Caldeira et al. 2007, Lima et al. 2009, Espírito-Santo et al. 2013).

Although intermediate and definitive hosts infected with $A$. cantonensis have been identified in Brazil, few cases of human infection have been reported to date. This situation could be interpreted simply as due to a lack of information about the parasite and its occurrence in Brazil. When CSF eosinophilia is detected, angiostrongyliasis should be considered in the differential diagnosis.

doi: 10.1590/0074-0276140023

Financial support: CAPES, CNPq, FAPERGS

+ Corresponding author: graeff.teixeira@gmail.com

Received 22 February 2014

Accepted 28 May 2014
This review focuses on the distribution of $A$. cantonensis in Brazil and provides basic information about the biology of this parasite, as well as the clinical aspects, diagnosis and recommended treatment of infection.

Biological aspects of A. cantonensis infection - Adult A. cantonensis worms are not found in infected humans. Rattus norvegicus is the main definitive host in which adult worms live inside the pulmonary arteries and produce the infective stage larvae (L1) for molluscs. In addition to $R$. norvegicus, other rodents may have a role as definitive hosts (Alicata 1965). These larvae are released inside the bronchial tree, swallowed and eliminated with the rats' faeces. Molluscs become infected both by ingestion of L1 or penetration of that larval form through the mollusc tegument. The larvae undergo two moults and produce the third stage (L3) that is eventually released along with the mollusc mucous secretions. Humans become infected after ingestion of L3 larvae; the parasites migrate to the central nervous system (CNS) where they moult twice (L4 and L5) and eventually die in the meninges.

Planarians, frogs, fishes, crabs, shrimps and lizards may serve as paratenic hosts of $A$. cantonensis. The parasite does not develop within these hosts, but they may be sources of infection (Ash 1968, Radomyos et al. 1994, Tsai et al. 2011).

Occurrence of A. cantonensis in Brazil - Naturally infected definitive and intermediate hosts have been found in several municipalities from northern to southern Brazil. A. cantonensis larvae from molluscs or adult worms in rats have been detected in the states of Paraná, São Paulo (SP), Rio de Janeiro (RJ), Pará, Bahia, Santa Catarina and Rio Grande do Sul (Figure, Table I) (Caldeira et al. 2007, Maldonado Júnior et al. 2010, Simões et al. 2011, Carvalho et al. 2012, Cognato et al. 2013). 
Several species of land snail can be served undercooked as a dish that is known in French cuisine as escargot. This term is also applied to commonly consumed molluscs, such as Helix pomatia (L.), Helix aspersa (L.) and Helix lucorum. Achatina fulica (Bowdich, 1822), the "giant African snail", is considered to have a high CA transmission potential because of its extensive presence in many parts of Brazil and its susceptibility to $A$. cantonensis infection (Thiengo et al. 2007, Vitta et al. 2011, Carvalho et al. 2012). Infected A. fulica and other land and freshwater molluscs have been found in many parts of Brazil (Table I).

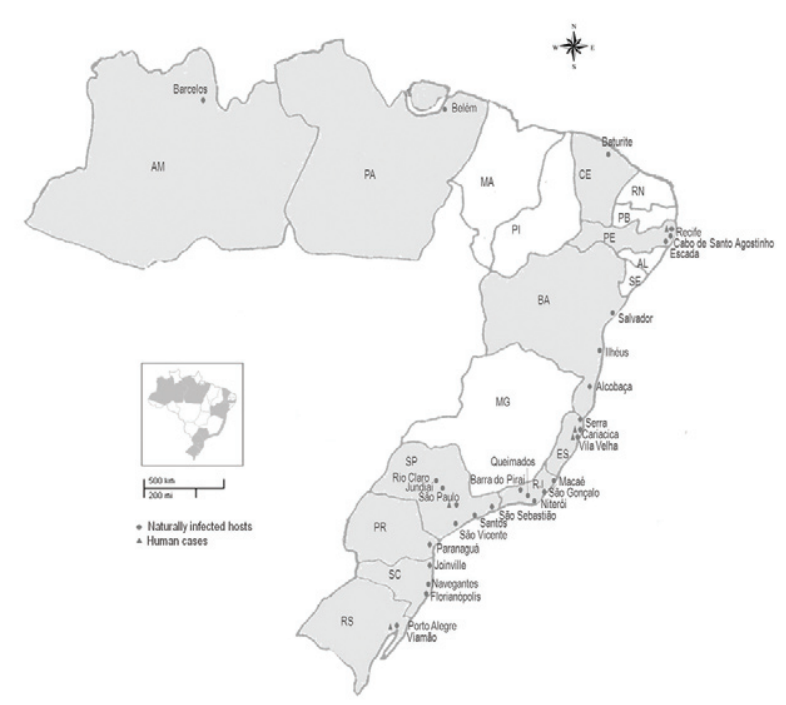

Distribution map of Angiostrongylus cantonensis and angiostrongyliasis cases in Brazil. AL: Alagoas; AM: Amazonas; BA: Bahia; CE: Ceará; ES: Espírito Santo; MA: Maranhão; MG: Minas Gerais; PA: Pará; PB: Paraíba; PE: Pernambuco; PI: Piauí; PR: Paraná; RJ: Rio de Janeiro; RN: Rio Grande do Norte; RS: Rio Grande do Sul; SC: Santa Catarina; SE: Sergipe; SP: São Paulo.

Human infection - Humans acquire A. cantonensis infection by eating raw or undercooked foods, such as snails, slugs, crustaceans (shrimp and crabs), frogs and bush meat (lizards). Condiments, salads, herbs and fruit juices (Tsai et al. 2004) may also contain L3 larvae from crushed molluscs or from mollusc slime trails (Bonetti $\&$ Graeff-Teixeira 1998). Infection may also occur by accidental ingestion during hand manipulation of molluscs in fisheries and/or during garden upkeep. Food from domestic vegetable gardens and ecological fairs may pose a higher risk of contamination, as the lack of industrial processing and pesticides may favour mollusc infection.

After ingestion, L3 larvae penetrate the intestinal walls, gain access to the bloodstream and migrate to the CNS. The presence of L3-L5 larvae in the meninges induces an eosinophilic inflammatory response.

The pathophysiology of CA is attributed primarily to larval movement and also involves proteolytic enzymes and pro-inflammatory and cytotoxic agents that are released by eosinophil granules. These enzymes and agents exacerbate cerebral tissue lesions together with vascular insufficiency due to inflammation, which may elicit permanent neurotrophic damage. This inflammatory process leads to larval death in the meninges, which in turn exacerbates inflammation.

Clinical manifestations - CA is an acute disease that may be asymptomatic and it is characterised by the spontaneous disappearance of symptoms within a few weeks; though very rarely, it can lead to severe sequelae (GraeffTeixeira et al. 2009). This disease is fatal in at least $3 \%$ of all cases (Eamsobhana \& Yong 2009).

The prepatent period may range from one day to three months post-infection, with symptoms occurring within two weeks in most cases (Sawanyawisuth et al. 2009). The clinical manifestations of CA depend on larval localisation; heavy infestations can produce encephalitis with severe neurological symptoms, coma and even death. Involvement of the spinal cord can produce radiculitis (Cooke-Yarborough et al. 1999).

The classical triad pattern of meningitis (headache, neck stiffness and fever) is frequently observed in patients with EoM, but all three symptoms are not always present. An extensive analysis of symptoms in 484 patients revealed that a headache was present in $99 \%$ of the patients, neck stiffness in $64 \%$ and fever in only $37 \%$ of the patients (Punyagupta et al. 1975). Other symptoms, such as diplopia or blurred vision (38\%), nausea (38\%) and vomiting (49\%) may be present. Less commonly reported symptoms include muscle weakness, orbital/ retro-orbital pain, ataxia, abdominal pain, body and extremity aches, convulsions, facial paralysis, somnolence and urinary retention/incontinence (Wang et al. 2008, Graeff-Teixeira et al. 2009, Sawanyawisuth et al. 2009). Ocular infection is a rare clinical manifestation $(\sim 1 \%)$ that may lead to permanent lesions and vision loss (Sawanyawisuth et al. 2007). Eosinophilic pneumonitis occurs in approximately $6 \%$ of the cases (Jin et al. 2008).

Diagnosis - CA is clinically diagnosed by a history of headaches, larval exposure within three months and evidence of eosinophilia in $>10 \%$ of the white blood cells in CSF (Ramirez-Avila et al. 2009, Sawanyawisuth et al. 2009). The laboratory examinations are discussed below. An initial complete blood count assessment is recommended in patients suspected of having EoM. Peripheral eosinophilia is common; an eosinophil count $>798$ in an individual at risk (e.g., due to a history of raw mollusc consumption) has shown $76.6 \%$ sensitivity, $80.2 \%$ specificity, a $58.1 \%$ positive predictive value and an $90.5 \%$ negative predictive value, which support the diagnosis of CA (Sawanyawisuth et al. 2010).

Imaging examination - Magnetic resonance imaging (MRI) has been recommended for the diagnosis of CA because it has identified abnormalities in many patients. Analyses of 74 patients who were infected with $A$. cantonensis using intravenous administration of gadolinium chelate revealed that the neuropathology of angiostrongyliasis includes cerebral congestion and thickened leptomeninges; multiple $150 \mu \mathrm{m}$ microcavities in the brain and spinal cord correlated with the migration 
TABLE I

Naturally infected hosts of Angiostrongylus cantonensis, municipalities and states where infected species were found in Brazil

\begin{tabular}{|c|c|c|}
\hline Species & States & Municipalities \\
\hline \multicolumn{3}{|l|}{ Molluscs } \\
\hline \multirow[t]{10}{*}{ Achatina fulica } & $\mathrm{AM}$ & Barcelos \\
\hline & BA & Alcobaça, Ilhéus \\
\hline & $\mathrm{CE}$ & Baturité \\
\hline & ES & Cariacica, Serra \\
\hline & PA & Belém \\
\hline & PR & Paranaguá \\
\hline & $\mathrm{PE}$ & Cabo de Santo Agostinho, Olinda, Recife \\
\hline & RJ & $\begin{array}{c}\text { Angra dos Reis, Barra do Piraí, Niterói, Nova Iguaçu, Rio de Janeiro, Queimados, } \\
\text { São Gonçalo }\end{array}$ \\
\hline & $\mathrm{SC}$ & Florianópolis, Joinville, Navegantes \\
\hline & SP & Jundiaí, Rio Claro, São Paulo \\
\hline \multirow[t]{4}{*}{ Bradybaena similaris } & BA & Ilhéus \\
\hline & ES & Cariacica, Serra \\
\hline & $\mathrm{SC}$ & Navegantes \\
\hline & SP & Santos \\
\hline Pomacea lineata & PE & Escada \\
\hline Sarasinula linguaeformis & SP & São Paulo \\
\hline \multirow[t]{5}{*}{ Sarasinula marginata } & BA & Salvador \\
\hline & ES & Cariacica, Vila Velha \\
\hline & PA & Belém \\
\hline & $\mathrm{RJ}$ & Niterói \\
\hline & SP & Santos, São Paulo \\
\hline \multirow[t]{5}{*}{ Subulina octona } & BA & Ilhéus \\
\hline & ES & Cariacica \\
\hline & PA & Belém \\
\hline & $\mathrm{PE}$ & Recife \\
\hline & SP & Santos, São Sebastião \\
\hline \multicolumn{3}{|l|}{ Rats } \\
\hline \multirow[t]{3}{*}{ Rattus norvegicus } & PA & Belém \\
\hline & RJ & São Gonçalo \\
\hline & RS & Porto Alegre \\
\hline Rattus rattus & PA & Belém \\
\hline
\end{tabular}

AM: Amazonas; BA: Bahia; CE: Ceará; ES: Espírito Santo; PA: Pará: PR: Paraná: PE: Pernambuco: RJ: Rio de Janeiro: RS: Rio Grande do Sul: SC: Santa Catarina: SP: São Paulo (Caldeira et al. 2007, Maldonado Júnior et al. 2010, Thiengo et al. 2010, Simões et al. 2011, Carvalho et al. 2012, Cognato et al. 2013, Espírito-Santo et al. 2013, Moreira et al. 2013).

and traffic patterns of larvae (Jin et al. 2005, 2008). Microhemorrhages, dilated perivascular spaces and Wallerian degeneration were also observed (Jin et al. 2005, 2008). However, in $55 \%$ of the patients with clinical symptoms of CA, no abnormalities were observed with MRI. Another MRI study involving 13 patients revealed varying degrees of meningeal enhancement and abnormal globus pallidus enhancement, but localised lesions were not observed (Tsai et al. 2003).

MRI is a valuable tool for the evaluation of CNS lesions. Abnormalities such as single or multiple enhancing lesions of the leptomeninges and brain parenchyma have been observed using MRI, but this modality cannot provide a definitive diagnosis without the concomitant use of other laboratory methods.

Microscopy - A definitive diagnosis of CA is very rarely based on the finding of parasitic larvae in a wetmount preparation of a fresh CSF sample. Biopsy can also rarely provide a diagnosis; one such case has been reported (Petjom et al. 2002). The patient was first diagnosed with an intramedullary spinal cord tumour, but histopathological analysis of a surgically excised tissue sample revealed eosinophilic infiltration and A. cantonensis larvae (Petjom et al. 2002). 
Laboratory investigation - The examination of CSF from patients with EoM reveals large numbers of eosinophils. The diagnosis of EoM is usually based on a CSF eosinophil count $\geq 10 \%$ of the cells or 10 eosinophils/ $\mathrm{mL}$. Importantly, at least two very atypical and fatal cases of encephalitis caused by $A$. cantonensis infection have occurred without CSF eosinophilia, but high levels of eosinophils were detected in the blood from these patients. Autopsies showed meningeal infiltration of eosinophils and the very rare development of adult worms in the lung arteries in both cases (Cooke-Yarborough et al. 1999, Lindo et al. 2004).

The infected CSF is clear, with no colour or turbidity, which allows the clinician to readily distinguish CA from other infections that may cause yellow coloration and viscosity, such as bacterial infections and some fungal infections. This characteristic also enables distinction from an infection by Gnathostoma spp nematodes that are common in Asian countries and that produce bloody CSF due to haemorrhagic parenchymal lesions. The CSF from patients with CA may also appear slightly cloudy, resembling coconut juice, which is pathognomonic of angiostrongyliasis (Sawanyawisuth \& Sawanyawisuth 2010). Biochemical analyses frequently show normal levels of glucose and protein; an elevated protein level is more common than a low glucose level (Punyagupta et al. 1975), most likely due to larval and tissue degradation that is mediated by eosinophil degranulation.

Immunology - Given the infrequency of a parasitological diagnosis of CA, e.g., the detection of larvae in CSF sediment, the use of indirect tests was studied. The majority of proposed assays use purified antigens, rather than crude extracts. In 1986, Chen (1986) observed that different fractions of purified antigens from juvenile or adult worms increased the sensitivity of ELISAs, though these antigens cross-reacted with Toxocara canis infection.

Subsequently, Akao et al. (1992) described two bands with molecular weights of 29-31 kDa from female adult worms that were potentially useful for an immunodiagnosis. Nuamtanong (1996) tested a whole crude antigen from female worms with ELISA and achieved 100\% sensitivity and $66.8 \%$ specificity regarding a diagnosis of CA. The author also tested the 31-kDa band using western blotting (WB) methods and observed cross-reactivity with trichinellosis, trichuriasis and opisthorchiasis in sera from infected patients.

Eamsobhana et al. (2001) purified the $31-\mathrm{kDa}$ component and reported that it demonstrated $100 \%$ sensitivity and specificity in a dot blot assay. The same group (Eamsobhana et al. 2013) recently proposed the use of the 31-kDa antigen in a dot immunogold filtration assay (DIGFA), which is more rapid while also demonstrating $100 \%$ sensitivity and specificity.

Another indirect approach to EoM diagnosis is the detection of $A$. cantonensis circulating antigen. Shih and Chen (1991) obtained a monoclonal antibody that recognises an $91-\mathrm{kDa}$ component from the excretion and secretion products of cultivated L3 larvae. In enzymelinked fluorescent assays, the antibody detected the 91$\mathrm{kDa}$ component in serum and CSF samples from infected patients with $88 \%$ sensitivity (Shih \& Chen 1991). In the same way, Chye et al. (1997) developed a monoclonal antibody that detects an antigen with a molecular weight of 204-kDa from L5 juveniles. This antibody showed greater sensitivity in CSF samples rather than serum samples.

These antigens are not widely available. Eamsobhana and Yong (2009) proposed the use of a purified 31-kDa antigen for an in-house kit preparation, but its use is restricted to Thailand. Our laboratory has sought to develop recombinant $31-\mathrm{kDa}$ antigens and make them widely available for diagnostic purposes. Some progress has been made; the composition, coding sequences and dependence on glycidic moieties for immunogenicity of the 31-kDa component have been identified (Morassutti et al. 2012). However, its expression in eukaryotic and prokaryotic systems has not yet produced satisfactory results (Morassutti et al. 2013). Although recombinant proteins are not available, the crude antigen has been employed for ELISAs and WB assays.

Molecular tests - Immunodiagnosis is not possible in the early stages of infection when anti-Angiostrongylus immunoglobulins have not been produced. In contrast, nucleic acids are present in CSF samples once nematode-specific cellular debris has been released into the subarachnoid space. Researchers initially sought to develop molecular tests for the identification of infected intermediate hosts for epidemiological studies and to differentiate Angiostrongylus larvae from those of many other nematodes that may infect molluscs. Caldeira et al. (2003) developed a polymerase chain reaction (PCR)restriction fragment length polymorphism test based on the amplification of ribosomal DNA internal transcribed spacer (ITS)2, followed by restriction enzyme cleavage. The authors suggested that this test could be used to diagnose CA (Caldeira et al. 2003). However, the US Centers for Disease Control and Prevention (CDC), in collaboration with a parasitology group from the Pontifical Catholic University of Rio Grande do Sul (PUCRS), Brazil, developed a sensitive quantitative real-time PCR method based on the amplification of ribosomal ITS1 that can detect DNA from the equivalent of less than one larva (Qvarnstrom et al. 2010). The CDC and PUCRS applied this real-time PCR test to human CSF samples and found that it was sufficiently sensitive to detect an amount of nucleic acid that was equivalent to less than one larva; these preliminary results show promise for the identification of infection in humans (Qvarnstrom et al. 2010).

CA in Brazil - In 2006, an human immunodeficiency virus-positive patient from RJ with a history of raw mollusc consumption presented with EoM. An ELISA test showed positivity for the $A$. cantonensis crude antigen. An extensive laboratory investigation led to the confirmation of no other aetiological diagnoses, suggesting that this case was the first observation of $A$. cantonensis infection in Brazil.

In 2007, two intoxicated men aged 22 and 39 years from Cariacica, in the southeastern state of Espírito Santo (ES), ate a raw snail (Sarasinula marginata was identified as the predominant species in that area) that was cut into two pieces, on a bet. After four days, the men developed 


\section{TABLE II}

Diagnosis of Angiostrongylus cantonensis infection in Brazilian individuals - Laboratory of Molecular Parasitology of Pontifical Catholic University of Rio Grande do Sul

\begin{tabular}{lc}
\hline $\begin{array}{l}\text { Case origin } \\
\text { city (state) }\end{array}$ & $\begin{array}{c}\text { Positive diagnosis/ } \\
\text { suspected cases }\end{array}$ \\
\hline Curitiba (PR) & $0 / 1$ \\
Distrito Federal & $0 / 1$ \\
(ES) & $3 / 5$ \\
Porto Alegre (RS) & $1 / 1$ \\
Porto Velho (RO) & $0 / 11$ \\
Recife (PE) & $9 / 27$ \\
(RJ) & $2 / 4$ \\
São José dos Pinhais (PR) & $1 / 1$ \\
Sao Paulo (SP) & $18 / 33$ \\
\hline Total & $34 / 84$ \\
\hline
\end{tabular}

ES: Espírito Santo; PE: Pernambuco; PR: Paraná; RJ: Rio de Janeiro; RO: Rondônia; RS: Rio Grande do Sul; SP: São Paulo.

abdominal and cervical pain, severe headache, myalgia, arthralgia, neck rigidity, disorientation, dysarthria and limb paralysis and presented at two different hospitals. The CSF eosinophil counts were $20-45 \%$. CA was diagnosed via reverse-transcription (RT)-PCR analysis of CSF samples (Garcia et al. 2008). Another case in ES involved a 20-month-old child from the city of Vila Velha who presented with the same symptoms (Caldeira et al. 2007).

A fatal case of EoM involving a 26-year-old woman was reported in 2009 in the city of Olinda, in the state of Pernambuco. The patient presented with $87 \%$ CSF eosinophilia, joint pain and somnolence. The diagnosis of CA was confirmed by RT-PCR analysis of a CSF sample (Lima et al. 2009).

In 2010, an 11-year-old boy in the city of São Paulo (SP) presented with a history of a headache for seven days, no fever, mild neck stiffness and 36\% CSF eosinophilia. RT-PCR analysis was negative for $A$. cantonensis infection, but infection was confirmed after 135 days of hospitalisation by positive serum conversion using an ELISA approach (Espírito-Santo et al. 2013). Many other cases of EoM have been diagnosed subsequently (Table II).

In 2013, a mentally deficient young male from the city of Viamão, adjacent to Porto Alegre (RS), presented with EoM. ELISA and WB analyses revealed a positive CA infection (unpublished observations). This case extended the area of EoM occurrence to the southernmost state in Brazil.

Although only a few cases of EoM due to $A$. cantonenis infection have been reported since the emergence of angiostrongyliasis in Brazil, our laboratory has supported many Brazilian health centres in the diagnosis of this disease. More than 80 examinations have been performed to date and at least 34 cases (including unpublished cases) have yielded positive ELISA results that were confirmed by RT-PCR or WB analyses (Table II). These data draw attention to the potential for identifying additional cases in the near future.

Differential diagnosis of EoM - Although A. cantonensis is the main causative agent of EoM, the disease may have other aetiological agents, including parasitic infection by Gnathostoma spp, cysticercus, Schistosoma spp, Toxocara spp and Trichinella spp, among others, as well as fungal, bacterial and viral infections [for a review, see Graeff-Teixeira et al. (2009)]. EoM also occurs in $30 \%$ of patients with intraventricular shunt malfunctions (Bezerra et al. 2011).

Treatment of $C A$ - The treatment of CA consists primarily of reducing the inflammatory response and relieving pain. The majority of hospitals in areas where the disease is most prevalent have adopted the administration of oral corticosteroids (prednisolone, $60 \mathrm{mg} / \mathrm{kg} /$ day) for 14 consecutive days (Sawanyawisuth 2008, Tseng et al. 2011). Intravenous administration may be necessary when the patient is unconscious.

The effectiveness of anthelmintic drugs for the treatment of CA remains unclear. A single placebo-controlled clinical trial has been conducted; it demonstrated the efficacy of treatment with albendazole $(15 \mathrm{mg} / \mathrm{kg}$ twice a day for 14 days) in 57 patients (Jitpimolmard et al. 2007). However, Prociv et al. (2000) postulated that anthelmintic administration causes greater damage due to the increased inflammatory reaction that is triggered by massive parasitic death. Thus, the concomitant use of anthelmintic and anti-inflammatory drugs (prednisolone, $60 \mathrm{mg} / \mathrm{day}$, and albendazole, $15 \mathrm{mg} / \mathrm{kg} / \mathrm{day}$, or mebendazole, $10 \mathrm{mg} / \mathrm{kg} / \mathrm{day}$, for two weeks) has been investigated (Chotmongkol et al. 2004).

Table III summarises the treatment regimens for EoM that is caused by A. cantonensis infection. A severe headache may persist for months in patients who receive only analgesic treatment. The administration of corticosteroids alone or in combination with anthelmintic therapy (e.g., albendazole or mebendazole) can significantly shorten the duration of a headache. However, a recent trial found no significant difference in the outcomes of corticosteroid and corticosteroid plus albendazole regimens (Chotmongkol et al. 2009). As mentioned above, anthelmintic therapy may not be favourable due to prolonged inflammatory processes. In clinical practice, a two-week course of corticosteroids is recommended in the absence of an obvious contraindication, such as diabetes or immunodeficiency. Minor side effects, such as transient facial oedema, may occur during the course of treatment. An open-label study using a one-week corticosteroid course showed a similar mean duration of headache (4.8 days) compared with other regimens (Sawanyawisuth et al. 2004), but the headache relapsed within two weeks in approximately $15 \%$ of the patients.

Supportive treatment should be provided to maintain patients' hydration and analgesic drugs should be administered for pain relief. Repeated lumbar punctures as needed to decrease intracranial pressure, thereby reducing pain symptoms, have also been recommended (Graeff-Teixeira et al. 2009). The severity of a headache declines rapidly following a lumbar puncture (Sawanyawisuth et al. 2004). 
TABLE III

Outcomes of various treatment regimens in eosinophilic meningitis caused by Angiostrongylus cantonensis

\begin{tabular}{lcccc}
\hline & Patients & Headache at 14 days & $\begin{array}{c}\text { Median duration } \\
\text { of headache } \\
\text { (days) }\end{array}$ & $\begin{array}{c}\text { n (\%) } \\
\text { Outcomes }\end{array}$ \\
\hline Placebo & 55 & $25(45.5)$ & $13(1-56)$ & Chotmongkol et al. (2000) \\
One week steroid & 52 & $8(15)$ & $4.8^{a}$ & Sawanyawisuth et al. (2004) \\
Two weeks steroid & 55 & $5(9.1)$ & $5(1-60)$ & Chotmongkol et al. (2000) \\
Two weeks albendazole & 34 & $7(20.6)$ & $8.9^{a}$ & Jitpimolmard et al. (2007) \\
Two weeks steroid with albendazole & 26 & $3(11.5)$ & 4 & Chotmongkol et al. (2004) \\
Two weeks steroid with albendazole & 53 & $0(0)$ & $3(1-14)$ & Chotmongkol et al. (2009) \\
Two weeks steroid with mebendazole & 41 & $4(9.8)$ & 3 & Chotmongkol et al. (2006) \\
\hline
\end{tabular}

$a$ : indicated mean value.

Ocular angiostrongyliasis - Ocular angiostrongyliasis manifests in approximately $1 \%$ of patients with A. cantonensis infection and may not be associated with EoM (Sawanyawisuth et al. 2007, Sinawat et al. 2008). This disease is not fatal, but it can permanently damage the affected eye. Prommindaroj et al. (1962) first observed the presence of parasites in the eyes of patients in Thailand in 1962. The main symptom of ocular angiostrongyliasis is blurred vision, which may persist for four days to eight weeks. A diagnosis is made by the indirect ophthalmoscopic observation of worms or by morphological identification of the parasite following surgical removal.

The surgical removal of parasites is recommended in the cases involving eye infections, but lesions may damage vision irreversibly (Sawanyawisuth et al. 2007). Oral and topical corticosteroid treatments can prevent the deterioration of vision that is due to the inflammation caused by laser or surgical procedures, but intravenous methylprednisolone, topical prednisolone, laser treatment and surgery did not result in improved vision in most cases (Sawanyawisuth et al. 2007, Sinawat et al. 2008).

Development of coma - Diffuse encephalitis occurs in a small proportion of patients, causing a permanent comatose condition with a high mortality rate (Chotmongkol \& Sawanyawisuth 2002). The risk factors for this encephalitic condition are age, fever and duration of headache, with adjusted odds ratios $(95 \%$ confidence intervals) of 1.22 (1.05-1.42), 37.05 (1.59-862.35) and 1.26 (1.03-1.55), respectively (Sawanyawisuth et al. 2009).

These data suggest that a missed diagnosis of EoM increases the risk of coma by $26 \%$ per day with prolonged headache. Pathological analysis has identified several larvae in the brain tissue of patients who develop a coma. According to the $A$. cantonensis life cycle, larvae should live in the subarachnoid spaces. A longer disease duration may increase the chance of larval migration to brain tissue and the consequent development of coma.

Prophylaxis - Personal hygiene and proper food preparation are essential to avoid $A$. cantonensis infection. The L3 larvae of Angiostrongylus spp remain infective even after 17 days of refrigeration at $5^{\circ} \mathrm{C}$ and mathematical models have estimated that approximately 80 days are required to eliminate the risk of infection by chilling as the sole larvicidal method (Richinitti et al. 1999). The use of bleach at a concentration of $1.5 \%$ at room temperature seems to be more promising, as it was shown to eliminate 97\% of infective larvae (Zanini \& Graeff-Teixeira 2001).

Snail or slug inclusions can be very small and go unnoticed during food preparation, especially when food is crushed or chopped. A classic study conducted in Guatemala during an abdominal angiostrongyliasis outbreak that was caused by a congeneric species, Angiostrongylus costaricensis (Morera \& Céspedes 1971), determined that the risk of infection was primarily associated with the consumption of fresh mint and shrimp (Kramer et al. 1998). Mint is used in the preparation of ceviche, a typical dish from the Pacific coastal areas of South America where seafood is prepared with herbs, including mint. In an outbreak of CA in Jamaica, Caesar salad was identified as the source of infection (Slom et al. 2002).

Brazilian food habits do not typically include exotic or raw meat, which may prevent the occurrence of a large number of cases of human A. cantonensis infection. In this setting, small children, people with mental dysfunctions, food handlers and gardeners may represent important risk groups. The control of mollusc populations is of health and environmental importance, especially with respect to the huge problem that is caused by the widespread dissemination of A. fulica.

Proposed diagnostic algorithm for CA - Based on our knowledge of angiostrongyliasis studies, we developed an algorithm to help diagnose potential new cases of CA: step 1 - The syndromic diagnosis of meningitis. Fever, headache and neck stiffness are the classical main elements for the diagnosis of meningitis. Meningitis that is caused by Angiostrongylus infection may manifest as a headache alone; step 2 - The syndromic diagnosis of EoM. A CSF examination can reveal increased cellularity and eosinophil numbers in infected patients. Some authors have considered the presence of a single eosinophil leukocyte to be abnormal, whereas others have defined CSF eosinophilia as affecting $>10 \%$ of the CSF leukocytes (Kuberski 1979, Weller 1993). For epidemiological surveillance in a new area of occurrence, such as Brazil, the presence of a single eosinophil leukocyte is the best 
criterion for the investigation of CA; step 3 - The consideration of an aetiological diagnosis of CA. If possible, the sediment from a CSF sample following step 2 should be reexamined to search for moving Angiostrongylus larvae. This finding is extremely rare, but it is the basis for a confirmed aetiological diagnosis of angiostrongyliasis; step 4 - The collection of epidemiological data that strongly support $A$. cantonensis as the cause of EoM. Such data include reported ingestion of raw molluscs or manipulation of snails and slugs during gardening. The patient's recent travel history, particularly to endemic areas such as Southeast Asia or the Pacific Islands, and consumption of raw exotic food should also be explored; step 5 - Immunodiagnosis and DNA detection. The following tests, which are available in the Brazilian reference diagnosis laboratory, should be performed: immunoglobulin G ELISA using the crude antigen, followed by WB analysis for the detection of the 31-kDa antigen and real-time PCR for the detection of DNA in CSF samples.

Collection of CSF and serum samples - The following instructions are useful to collect and send serum and CSF samples for laboratory tests: at least $250 \mu \mathrm{L}$ of CSF should be frozen immediately at $-20^{\circ} \mathrm{C}$ for serology and PCR analysis. Venous blood $(5 \mathrm{~mL})$ should be collected without an anticoagulant. After spontaneous or accelerated blood clotting by incubation at $37^{\circ} \mathrm{C}$ in a water bath for $20 \mathrm{~min}$, the blood samples should be centrifuged and the serum (supernatant) removed. Store the serum in aliquots of approximately $100 \mu \mathrm{L}$ with proper identification of the patient's name and date.

Analysis of infected molluscs - The following instructions are useful to collect and send land snails for parasitological examination: it is much easier to collect terrestrial molluscs early in the morning or at night because they are active. It is important to use gloves to avoid direct contact with the snails while collecting them. As they must be sent alive for the detection of nematode larvae, confirm that they are all alive before wrapping each snail using a paper towel or another similar material. Then, put them all into a plastic bag or a jar and place the package into an appropriate box that is used to transport biological samples. It is not necessary to include ice or anything else that keeps them refrigerated. Include a label with the local collection site and date of collection, in addition to the name of the collector and the epidemiological data, if possible.

$\mathrm{CA}$ is an emerging disease in Brazil and the medical community needs to be aware of its presence in order to diagnose novel cases. Cell differentiation analysis should be performed on patients with meningeal syndrome and increased CSF cell counts. The presence of eosinophils in CSF samples should prompt serological testing and PCR analysis of angiostrongyliasis and other less common aetiologies. A protocol that can be applied at sentinel hospitals and laboratories that perform CSF examinations is being established across the country as a measure to monitor the occurrence of CA. A second important set of criteria comes from the assessment of CA risk, including a history of raw mollusc or fish consumption, recent garden manipulation or other types of contact with molluscs or paratenic hosts. Clinicians must also be aware that people who have travelled to endemic areas may return to Brazil with $A$. cantonensis infection. CA should be suspected in a patient with a severe headache and a positive risk history, even when an eosinophil is not detected in a CSF sample. Increased awareness of the presence of $A$. cantonensis and thus potential infection, in a new geographic area may result in a much larger number of diagnoses and improved knowledge of the distribution and public health importance of this disease.

\section{REFERENCES}

Aguiar PH, Morera P, Pascual J 1981. First record of Angiostrongylus cantonensis in Cuba. Am J Trop Med Hyg 30: 963-965.

Akao N, Kondo k, Ohyama T, Chen E, Sano M 1992. Antigens of adult female worm of Angiostrongylus cantonensis recognized by infected humans. Kisechugaku Zasshi 41: 225-230.

Ash LR 1968. The occurrence of Angiostrongylus cantonensis in frogs of New Caledonia with observations on paratenic hosts of metastrongyles. J Parasitol 54: 432-436.

Bezerra S, Frigeri TM, Severo CM, Santana JC, Graeff-Teixeira C 2011. Cerebrospinal fluid eosinophilia associated with intraventricular shunts. Clin Neurol Neurosurg 113: 345-349.

Bonetti VC, Graeff-Teixeira C 1998. Angiostrongylus costaricensis and the intermediate hosts: observations on elimination of L3 in the mucus and inoculation of L1 through the tegument of mollucs. Rev Soc Bras Med Trop 31: 289-294.

Caldeira RL, Carvalho OS, Mendonça CLFG, Graeff-Teixeira C, Silva MCF, Ben R, Maurer R, Lima WS, Lenzi HL 2003. Molecular differentiation of Angiostrongylus costaricensis, A. cantonensis and $A$. vasorum by polymerase chain reaction-restriction fragment length polymorphism. Mem Inst Oswaldo Cruz 98: 1039-1043.

Caldeira RL, Mendonça CLGF, Goveia CO, Lenzi HL, Graeff-Teixeira C, Lima WS, Mota EM, Pecora IL, de Medeiros AMZ, Carvalho OS 2007. First record of molluscs naturally infected with Angiostrongylus cantonensis (Chen, 1935) (Nematoda: Metastrongylidae) in Brazil. Mem Inst Oswaldo Cruz 102: 887-889.

Carvalho OS, Scholte RGC, de Mendonça CLF, Passos LKJ, Caldeira RL 2012. Angiostrongylus cantonensis (Nematode: Metastron-gyloidea) in molluscs from harbour areas in Brazil. Mem Inst Oswaldo Cruz 107: 740-746.

Chen SN 1986. Enzyme-linked immunosorbent assay (ELISA) for the detection of antibodies to Angiostrongylus cantonensis. Trans $R$ Soc Trop Med Hyg 80: 398-405.

Chotmongkol V, Kittimongkolma S, Niwattayakul K, Intapan PM, Thavornpitak Y 2009. Comparison of prednisolone plus albendazole with prednisolone alone for treatment of patients with eosinophilic meningitis. Am J Trop Med Hyg 81: 443-445.

Chotmongkol V, Sawadpanitch K, Sawanyawisuth K, Louhawilai S, Limpawattana P 2006. Treatment of eosinophilic meningitis with a combination of prednisolone and mebendazole. Am J Trop Med Hyg 74: 1122-1124.

Chotmongkol V, Sawanyawisuth K 2002. Clinical manifestations and outcome of patients with severe eosinophilic meningoencephalitis presumably caused by Angiostrongylus cantonensis. Southeast Asian J Trop Med Public Health 33: 231-234.

Chotmongkol V, Sawanyawisuth K, Thavornpitak Y 2000. Corticosteroid treatment of eosinophilic meningitis. Clin Infect Dis 31: $660-662$.

Chotmongkol V, Wongjitrat C, Sawadpanit K, Sawanyawisuth K 2004. Treatment of eosinophilic meningitis with a combination of albendazole and corticosteroid. Southeast Asian J Trop Med Public Health 35: 172-174. 
Chye SM, Yen CM, Chen ER 1997. Detection of circulating antigen by monoclonal antibodies for immunodiagnosis of angiostrongyliasis. Am J Trop Med Hyg 56: 408-412.

Cognato BB, Morassutti AL, da Silva AA, Graeff-Teixeira C 2013. First report of Angiostrongylus cantonensis in Porto Alegre, Rio Grande do Sul, southern Brazil. Rev Soc Bras Med Trop 46: 664-665.

Cooke-Yarborough CM, Kornberg AJ, Hogg GG, Spratt DM, Forsyth JRL 1999. A fatal case of angiostrongyliasis in an 11-month-old infant. Med J Aust 170: 541-543.

Eamsobhana P, Gan XX, Ma A, Wang Y, Wanachiwanawin D, Yong HS 2013. Dot immunogold filtration assay (DIGFA) for the rapid detection of specific antibodies against the rat lungworm Angiostrongylus cantonensis (Nematoda: Metastrongyloidea) using purified 31-kDa antigen. J Helminthol 28: 1-6.

Eamsobhana P, Yong HS 2009. Immunological diagnosis of human angiostrongyliasis due to Angiostrongylus cantonensis (Nematoda: Angiostrongylidae). Int J Infect Dis 13: 425-431.

Eamsobhana P, Yoolek A, Suvouttho S, Suvuttho S 2001. Purification of a specific immunodiagnostic Parastrongylus cantonensis antigen by electroelution from SDS-polyacrylamide gels. Southeast Asian J Trop Med Public Health 32: 308-313.

Espírito-Santo MC, Pinto PL, da Mota DJ, Gryschek RC 2013. The first case of Angiostrongylus cantonensis eosinophilic meningitis diagnosed in the city of São Paulo, Brazil. Rev Inst Med Trop Sao Paulo 55: 129-132.

Garcia MH, Moraes C, Almada GL, Carvalho OS, Caldeira RL, Mendonça CL, Zanon DM, Antunes FA, Santelli AC, Castro S, Obara MT, Reis AK, de Araujo WN 2008. First reported outbreak of eosinophilic meningitis caused by Angiostrongylus cantonensis in Brazil. Available from: cdc.gov/eid/pdfs/ICEID2008.pdf.

Graeff-Teixeira C, da Silva AC, Yoshimura K 2009. Update on eosinophilic meningoencephalitis and its clinical relevance. Clin Microbiol Rev 22: 322-348.

Jin E, Ma D, Liang Y, Ji A, Gan S 2005. MRI findings of eosinophilic myelomeningoencephalitis due to Angiostrongylus cantonensis. Clin Radiol 60: 242-250.

Jin EH, Ma Q, Ma DQ, He W, Ji AP, Yin CH 2008. Magnetic resonance imaging of eosinophilic meningoencephalitis caused by Angiostrongylus cantonensis following eating freshwater snails. Chin Med J 121: 67-72.

Jitpimolmard S, Sawanyawisuth K, Morakote N, Vejjajiva A, Puntumetakul M, Sanchaisuriya K, Tassaneeyakul W, Korwanich N 2007. Albendazole therapy for eosinophilic meningitis caused by Angiostrongylus cantonensis. Parasitol Res 100: 1293-1296.

Kim DY, Stewart TB, Bauer RW, Mitchell M 2002. Parastrongylus (= Angiostrongylus) cantonensis now endemic in Louisiana wildlife. J Parasitol 88: 1024-1026.

Kramer MH, Greer GJ, Quinonez JF, Padilla NR, Hernandez B, Arana BA, Lorenzana R, Morera P, Hightower AW, Eberhard ML, Herwaldt BL 1998. First reported outbreak of abdominal angiostrongyliasis. Clin Infect Dis 26: 365-372.

Lima AR, Mesquita SD, Santos SS, Aquino ER, Rosa LR, Duarte FS, Teixeira AO, Costa ZR, Ferreira ML 2009. Alicata disease: neuroinfestation by Angiostrongylus cantonensis in Recife, Pernambuco, Brazil. Arq Neuropsiquiatr 67: 1093-1096.

Lindo JF, Escoffery CT, Reid B, Codrington G, Cunningham-Myrie C, Eberhard ML 2004. Fatal autochthonous eosinophilic meningitis in a Jamaican child caused by Angiostrongylus cantonensis. Am J Trop Med Hyg 70: 425-428.

Maldonado Júnior A, Simões RO, Oliveira APM, Motta EM, Fernandez MA, Pereira ZM, Monteiro SS, Torres EJL, Thiengo SC 2010. First report of Angiostrongylus cantonensis (Nematoda: Metastrongylidae) in Achatina fulica (Mollusca: Gastropoda) from Southeast and South Brazil. Mem Inst Oswaldo Cruz 105: 938-941.

Morassutti AL, Levert K, Perelygin A, da Silva AJ, Wilkins P, GraeffTeixeira C 2012. The 31-kDa antigen of Angiostrongylus cantonensis comprises distinct antigenic glycoproteins. Vector Borne Zoonotic Dis 12: 961-968.

Morassutti AL, Perelygin A, Levert K, Lin SC, Lee YM, da Silva AJ, Wilkins PP, Graeff-Teixeira C 2013. Expression of recombinant antigenic proteins from Angiostrongylus cantonensis: a brief report. Hawaii J Med Public Health 72 (Suppl. 2): 58-62.

Moreira VLC, Giese EG, Melo FTV, Simões RO, Thiengo SC, Maldonado JYA, Santos JN 2013. Endemic angiostrongyliasis in the Brazilian Amazon: natural parasitism of Angiosntrongylus cantonensis in Rattus rattus and R. norvergicus and sympatric giant African land snails, Achatina fulica. Acta Trop 125: 90-97.

Nuamtanong S 1996. The evaluation of the 29 and $31 \mathrm{kDa}$ antigens in female Angiostrongylus cantonensis for serodiagnosis of human angiostrongyliasis. Southeast Asian J Trop Med Public Health 27: 291-296.

Petjom S, Chaiwun B, Settakorn J, Visrutaratna P, Rangdaeng S, Thorner PS 2002. Angiostrongylus cantonensis infection mimicking a spinal cord tumor. Ann Neurol 52: 99-101.

Pincay T, García L, Narváez E, Decker O, Martini L, Moreira JM 2009. Angiostrongyliasis due to Parastrongylus (Angiostrongylus) cantonensis in Ecuador. First report in South America. Trop Med Int Health 14 (Suppl. 2): S37.

Prociv P, Spratt DM, Carlisle MS 2000. Neuro-angiostrongyliasis: unresolved issues. Int J Parasitol 30: 1295-1303.

Prommindaroj K, Leelawongs N, Pradatsundarasar A 1962. Human angiostrongyliasis of the eye in Bangkok. Am J Trop Med Hyg 1: 759-761.

Punyagupta S, Juttijudata P, Bunnag T 1975. Eosinophilic meningitis in Thailand. Clinical studies of 484 typical cases probably caused by Angiostrongylus cantonensis. Am J Trop Med Hyg 24: 921-931.

Qvarnstrom Y, da Silva AC, Teem JL, Hollingsworth R, Bishop H, Graeff-Teixeira C, da Silva AJ 2010. Improved molecular detection of Angiostrongylus cantonensis in mollusks and other environmental samples with a species-specific internal transcribed spacer 1-based TaqMan assay. Appl Environ Microbiol 76: 5287-5289.

Radomyos P, Tungtrongchitr A, Praewanich R, Khewwatchan P, Kantangkul T, Junlananto P, Ayudhya SI 1994. Occurrence of the infective stage of Angiostrongylus cantonensis in the yellow tree monitor (Varanus bengalensis) in five provinces of Thailand. Southeast Asian J Trop Med Public Health 25: 498-500.

Ramirez-Avila L, Slome S, Schuster FL, Gavali S, Schantz PM, Sejvar J, Glaser CA 2009. Eosinophilic meningitis due to Angiostrongylus and Gnathostoma species. Clin Infect Dis 48: 322-327.

Richinitti LM, Fonseca NA, Graeff-Teixeira C 1999. The effect of temperature on mobility of Angiostrongylus costaricensis third stage larvae. Rev Inst Med Trop Sao Paulo 41: 225-228.

Sawanyawisuth K 2008. Treatment of angiostrongyliasis. Trans $R$ Soc Trop Med Hyg 102: 990-996.

Sawanyawisuth K, Kitthaweesin K, Limpawattana P, Intapan PM, Tiamkao S, Jitpimolmard S, Chotmongkol V 2007. Intraocular angiostrongyliasis: clinical findings, treatments and outcomes. Trans R Soc Trop Med Hyg 101: 497-501.

Sawanyawisuth K, Limpawattana P, Busaracome P, Ninpaitoon B, Chotmongkol V, Intapan PM, Tanawirattananit S 2004. A 1-week course of corticosteroids in the treatment of eosinophilic meningitis. Am J Med 117: 802-803. 
Sawanyawisuth K, Sawanyawisuth K 2010. Drug target in eosinophilic meningitis caused by Angiostrongylus cantonensis. Infect Disord Drug Targets 10: 322-328.

Sawanyawisuth K, Sawanyawisuth K, Senthong V, Limpawattana P, Intapan PM, Tiamkao S, Jitpimolmard S, Chotmongkol V, Barrett-Connor E 2010. Peripheral eosinophilia as an indicator of meningitic angiostrongyliasis in exposed individuals. Mem Inst Oswaldo Cruz 105: 942-944.

Sawanyawisuth K, Takahashi K, Hoshuyama T, Senthong V, Limpawattana P, Intapan PM, Wilson D, Tiamkao S, Jitpimolmard S, Chotmongkol V 2009. Clinical factors predictive of encephalitis caused by Angiostrongylus cantonensis. Am J Trop Med Hyg 81: 698-701.

Shih HH, Chen SN 1991. Immunodiagnosis of angiostrongyliasis with monoclonal antibodies recognizing a circulating antigen of mol. wt 91,000 from Angiostrongylus cantonensis. Int $J$ Parasitol 21: 171-177.

Simões RO, Monteiro FA, Sanchez E, Thiengo SC, Garcia JS, CostaNeto SF, Luque JL, Maldonado A 2011. Endemic angiostrongyliasis, Rio de Janeiro, Brazil. Emerg Infect Dis 17: 1331-1333.

Sinawat S, Sanguansak T, Angkawinijwong T, Ratanapakorn T, Intapan PM, Yospaiboon Y 2008. Ocular angiostrongyliasis: clinical study of three cases. Eye 22: 1446-1448.

Slom TJ, Cortese MM, Gerber SI, Jones RC, Holtz TH, Lopez AS, Zambrano CH, Sufit RL, Sakolvaree Y, Chaicumpa W, Herwaldt BL, Johnson S 2002. An outbreak of eosinophilic meningitis caused by Angiostrongylus cantonensis in travelers returning from the Caribbean. N Engl J Med 346: 668-675.

Thiengo SC, Faraco FA, Salgado NC, Cowie RH, Fernandez MA 2007. Rapid spread of an invasive snail in South America: the giant African snail, Achatina fulica, in Brasil. Biol Invasions 9: 693-702.

Thiengo SC, Maldonado A, Mota EM, Torres EJ, Caldeira R, Carvalho OS, Oliveira AP, Simões RO, Fernandez MA, Lanfredi RM
2010. The giant African snail Achatina fulica as natural intermediate host of Angiostrongylus cantonensis in Pernambuco, Northeast Brazil. Acta Trop 115: 194-199.

Tsai HC, Lai PH, Sy CL, Lee SS, Yen CM, Wann SR, Chen YS 2011. Encephalitis caused by Angiostrongylus cantonensis after eating raw frogs mixed with wine as a health supplement. Intern Med 50: 771-774.

Tsai HC, Lee SS, Huang CK, Yen CM, Chen ER, Liu YC 2004. Outbreak of eosinophilic meningitis associated with drinking raw vegetable juice in southern Taiwan. Am J Trop Med Hyg 71: 222-226.

Tsai HC, Liu YC, Kunin CM, Lai PH, Lee SS, Chen YS, Wann SR, Lin WR, Huang CK, Ger LP, Lin HH, Yen MY 2003. Eosinophilic meningitis caused by Angiostrongylus cantonensis associated with eating raw snails: correlation of brain magnetic resonance imaging scans with clinical findings. Am J Trop Med Hyg 68: 281-285.

Tseng YT, Tsai HC, Sy CL, Lee SS, Wann SR, Wang YH, Chen JK, Wu KS, Chen YS 2011. Clinical manifestations of eosinophilic meningitis caused by Angiostrongylus cantonensis: 18 years' experience in a medical center in southern Taiwan. $J$ Microbiol Immunol Infect 44: 382-389.

Vitta A, Polseela R, Nateeworanart S, Tattiyapong M 2011. Survey of Angiostrongylus cantonensis in rats and giant African land snails in Phitsanulok province, Thailand. Asian Pac J Trop Med 4: 597-599.

Wang QP, Lai DH, Zhu XQ, Chen XG, Lun ZR 2008. Human angiostrongyliasis. Lancet Infect Dis 8: 621-630.

Weller PF 1993. Eosinophilic meningitis. Am J Med 95: 250-253.

Zanini GM, Graeff-Teixeira C 2001. Inactivation of infective larvae of Angiostrongylus costaricensis with short time incubations in $1.5 \%$ bleach solution, vinegar or saturated cooking salt solution. Acta Trop 78: 17-21. 